\title{
Electrophoretic field gradient focusing with on-column detection by fluorescence quenching $\dagger$
}

\author{
Richard J. Ansell, ${ }^{* a}$ Pilar González Tuñon, ${ }^{a d}$ Yating Wang, ${ }^{a}$ Peter Myers, ${ }^{a e}$ Cornelius F. Ivory, \\ Jeffrey N. Keen ${ }^{c}$ and John B. C. Findlay ${ }^{c}$
}

\author{
Received 4th September 2008, Accepted 10th December 2008 \\ First published as an Advance Article on the web 24th December 2008 \\ DOI: $10.1039 / b 815446 e$
}

\begin{abstract}
Native, uncoloured, proteins can be focused in a column containing a fluorescent packing material, using hydrodynamic flow and a counteracting non-linear electric field, and imaged along the length of the channel by fluorescence quenching.
\end{abstract}

Electric field gradient focusing ${ }^{1-4}$ (FGF, also known as electric field focusing or electromobility focusing) is an emerging technique for the separation of ions based on their electrophoretic mobility in a column, where a hydrodynamic flow in one direction is opposed by a curved electric field. It is a member of the family of equilibrium gradient methods, also including isoelectric focusing (IEF), and temperature gradient focusing (TGF), ${ }^{5,6}$ and like these has been adapted to a microchannel/chip format. ${ }^{7-9}$ It offers an alternative to conventional electrophoretic techniques for protein separation and proteomics.

Focusing techniques are potentially more sensitive than straightforward electrophoretic techniques (native PAGE, CE) where the field is constant and broadening increases with migration distance. FGF also has a potential advantage over conventional protein electrofocusing techniques. In gel IEF and capillary IEF a constant electric field is opposed by a $\mathrm{pH}$ gradient, and focusing occurs at the isoelectric point of the protein, which often causes problems with protein precipitation. In FGF the $\mathrm{pH}$ is constant throughout the chamber and focusing does not occur at the $\mathrm{pI}$, so that higher sample concentrations may be accommodated.

The FGF instrument designed by Lee et al. and Woolley et al. is based on a shaped ionically conducting membrane surrounding the separation channel. ${ }^{10-15}$ As the membrane becomes narrower, the field strength increases. The design adopted by Ivory et al. uses an array of electrodes, separated from the separation channel by a dialysis membrane, and under individual control, which produces an electric field which can be shaped at will ${ }^{16-18}$ (Fig. 1). Because of the capacity to change the electric field during a run, this version of the technique was dubbed dynamic field gradient focusing, DFGF. By dynamic control of the shape of the electric field, the point at which an analyte ion focuses may be moved up or down and analytes teased apart.

${ }^{a}$ School of Chemistry, University of Leeds, Leeds, UK. E-mail: chmrja@ leeds.ac.uk; Fax: +44 (0)113 3436565; Tel: +44 (0)113 3436415

${ }^{b}$ Department of Chemical Engineering, Washington State University, Pullman, WA, USA

${ }^{c}$ Faculty of Biological Sciences, University of Leeds, Leeds, UK

${ }^{d}$ York Bioanalytical Solutions Ltd., York, UK

${ }^{e}$ Department of Chemistry, University of Liverpool, Liverpool, UK

$\dagger$ Electronic supplementary information (ESI) available: experimental conditions for synthesis of $\mathrm{F}_{254}$-containing cross-linked polyacrylamide. See DOI: $10.1039 / \mathrm{b} 815446 \mathrm{e}$
Other FGF designs have included focusing in a dialysis membrane with a conductivity gradient established along its length by a counterflowing low ionic strength buffer outside the membrane. ${ }^{19}$ This principle can be usefully adopted in Ivory's instrument also. ${ }^{18}$

In monitoring the separation on-column, Ivory and co-workers have mostly used coloured compounds, including coloured and dyelabelled proteins, ${ }^{16,17}$ and optical camera detection, while the Lee and Woolley groups have mostly used fluorescent/fluorescent-labelled proteins and laser-induced fluorescence. ${ }^{10-15}$ Of course this excludes the vast majority of native proteins, and a similar limitation is found in work up to now on microchannel IEF and TGF. ${ }^{5,6}$ Fluorescent labelling of proteins complicates mass spectrometric analysis and can change the electrophoretic mobilities of proteins (particularly if the

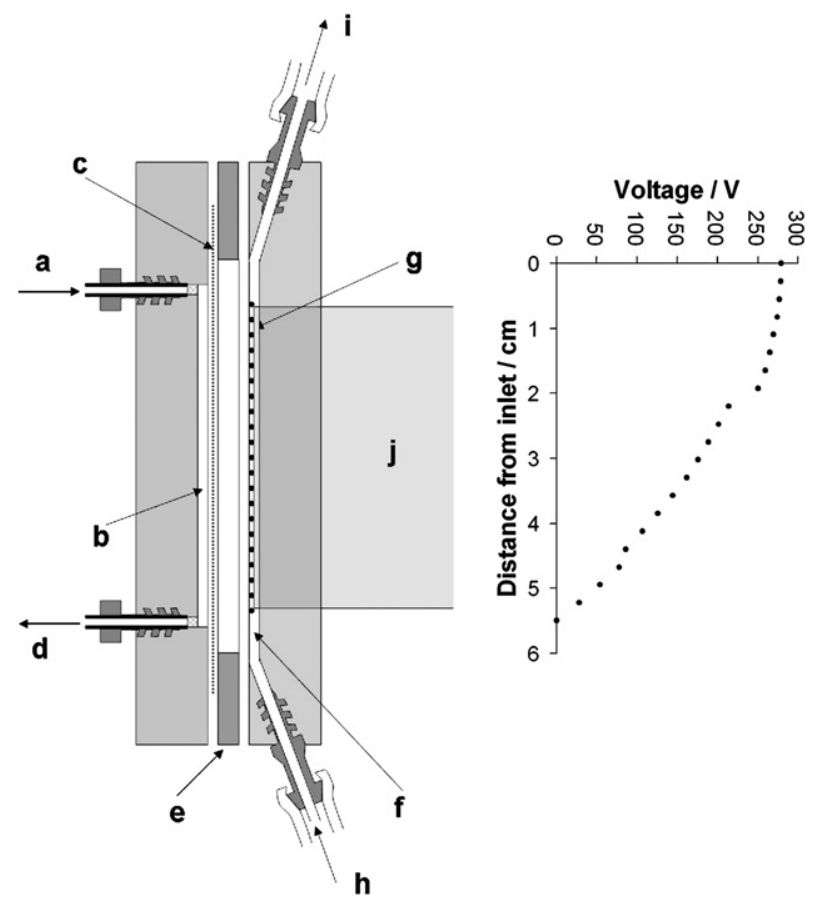

Fig. 1 Exploded cross-sectional schematic of the front block, spacer, and middle block, together with the voltage profile used in this work: (a) running buffer flow enters front via $1 / 16^{\prime \prime}$ tubing and threaded fritted adaptor; (b) $5.7 \mathrm{~cm}$ long separation channel containing packing material; (c) dialysis membrane; (d) running buffer exits; (e) spacer with $6.7 \mathrm{~cm}$ long cut channel; (f) $5.7 \mathrm{~cm}$ long electrode channel cut in back block; (g) 21 platinum wire electrodes (stretched between electrode pins); (h) coolant flow enters via barbed adaptor; (i) coolant exits; (j) glass slide for introducing UV. 
label is ionisable), so that in the case of inhomogeneous labelling peaks would be artificially broadened. Monitoring native proteins by UV absorbance, however, would require UV-transparent materials, e.g. quartz glass, which add significantly to the cost of prototype devices, while the array of electrodes required in DFGF would seem to preclude UV transmittance perpendicular to the separation channel along the whole of its length.

Both the Lee and Woolley groups and Ivory et al. have also studied the conditions under which analytes are eluted from the separation channel, ${ }^{13,17}$ using post-column detectors, which would be necessary, for example, to enable structural identification of unknown proteins by mass spectrometry. An ideal system might combine on-channel and post-channel detection, in order to ensure that analytes are teased apart and eluted one at a time.

A DFGF system allowing on-column detection of native, uncoloured proteins is presented here for the first time, based on quenching of fluorescence of manganese-activated zinc silicate $\left(\mathrm{F}_{254}\right.$ indicator, EM Science, $\lambda_{\mathrm{ex}}=254 \mathrm{~nm}, \lambda_{\mathrm{em}}=500 \mathrm{~nm}$, a material commonly used in fluorescent thin-layer chromatography plates). The mechanism of quenching, as in TLC, is the absorbance of the excitation radiation by the analyte. ${ }^{20}$ The device was based closely on the DFGF system used by Tuñón et al. ${ }^{18}$ (Fig. 1). The rear block, containing the electrode array, also contained a $50 \times 50 \times 1 \mathrm{~mm}$ UV glass slide (Comar) which extended $10 \mathrm{~mm}$ into the Plexiglass ${ }^{\circledR}$ (poly(methyl methacrylate)) and protruded $40 \mathrm{~mm}$ out of the back. The edge inside the block was exposed to the coolant channel, and the $0.25 \mathrm{~mm}$ diameter platinum wire (Aldrich) electrodes were stretched at intervals of $0.1^{\prime \prime}$ between channels either side of the glass, attaching to the pins of two male-female connector strips (Samtec). There was a $0.5 \mathrm{~mm}$ gap between the edge of the glass slide and the wire electrodes, and a 0.25 $\mathrm{mm}$ gap between the wires and the surface of the rear block. With the $3.2 \mathrm{~mm}$ thick black Teflon ${ }^{\otimes}$ (polytetrafluoroethylene) spacer in place, this meant a gap of $3.45 \mathrm{~mm}$ between the electrodes and the dialysis membrane (Spectrum, Spectra/Por cellulose acetate membrane, molecular weight cut-off $=100 \mathrm{Da}$ ) which separated the coolant channel from the separation channel.

The $57 \mathrm{~mm}$ long, $1 \mathrm{~mm}$ wide and $0.5 \mathrm{~mm}$ deep separation channel machined into the front block was packed with cross-linked polyacrylamide beads containing $0.5 \% \mathrm{w} / \mathrm{w} \mathrm{F}_{254}$ indicator (Fig. 2). The beads were prepared by suspension polymerisation using an aqueous reacting phase and organic dispersing phase in the presence of the $\mathrm{F}_{254}$ indicator particles (see ESI $\dagger$ ). ${ }^{21}$ Although the particles are not all spherical and there is a distribution of particle sizes, this is not expected to influence the efficiency of the focusing. Unlike in

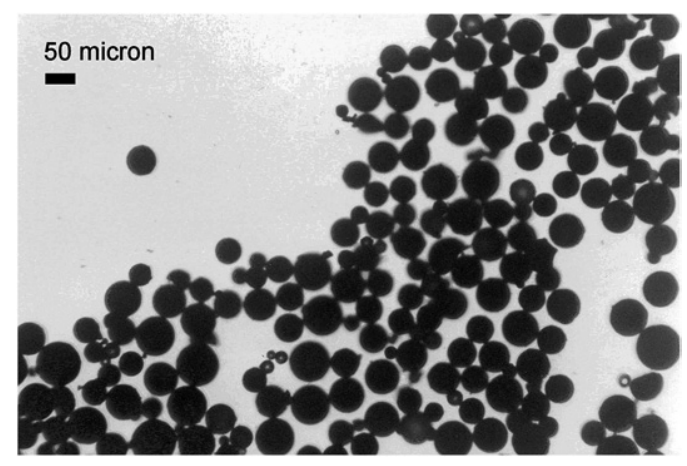

Fig. 2 Polyacrylamide packing material containing $\mathrm{F}_{254}$ indicator.
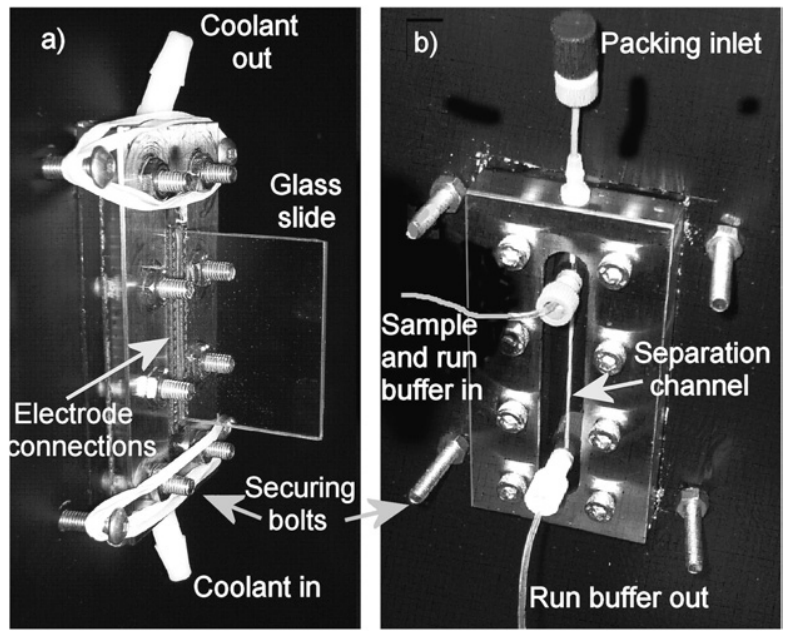

Fig. 3 Rear chamber (a) and front chamber (b) showing the device in place and the tubing for fluidics. The electrode connections are not in place for clarity.

chromatography, the packing in FGF is present only in order to reduce the diffusion of analyte in the separation channel. The presence of differing paths through the channel is not detrimental since there will still nonetheless be only one point at which the hydrodynamic flow balances the electrophoretic force. Moreover, since the flow rate used here is very low $\left(20 \mu \mathrm{L} \mathrm{h}^{-1}\right)$ the additional backpressure generated by using a packing with a heterogeneous size distribution is also insignificant. The remaining dimensions of the device and details of connections and auxiliary pumps etc. were exactly as in the previous work. ${ }^{18}$ The device was placed in a purposebuilt cabinet with a rear compartment and front compartment separated by a black-painted Plexiglass ${ }^{\circledR}$ screen containing a gap into which the device fitted (Fig. 3). The rear block (with the glass slide protruding) was in the rear compartment close by a $6 \mathrm{~W} 254 \mathrm{~nm}$ lamp (UV Products, UVS 16-EL) and the front block, containing the separation channel, was in the front compartment where it was faced at a distance of $28 \mathrm{~cm}$ by a CCD camera (Diagnostic Instruments SPOT Insight 4, with a Nikon $50 \mathrm{~mm} 1: 1.4$ lens). Photographs were collected using the SPOT Advanced software running on a Pentium 4 PC, converted to .jpg format and intensity histograms were derived using Scion Image processing software (Scion Corporation).

By trial and error the optimal position of the UV lamp was found to be $4 \mathrm{~cm}$ behind the rear edge of the glass slide, and $2 \mathrm{~cm}$ to the side of it, such that UV light was incident on the slide at a grazing angle of approximately $20 \%$.

Proteins were introduced into the separation channel via an injection valve (Upchurch Scientific) with a $10 \mu \mathrm{L}$ sample loop, introduced into the $\mathrm{pH} 8.6100 \mathrm{mM}$ Tris run buffer at a flow rate of $20 \mu \mathrm{L} \mathrm{h}^{-1}$. The coolant buffer was $\mathrm{pH} 8.61 \mathrm{mM}$ Tris, pumped in the counter direction at $\sim 5 \mathrm{~mL} \mathrm{~s}^{-1}$. The electric field shown in Fig. 1 was switched on once the protein had entered the channel. Fig. 4a and 4b show the focusing of horse liver alcohol dehydrogenase (HLADH, from which NAD had been removed by gel filtration) and horseshoe crab hemocyanin (HC) injected separately, after $\sim 5 \mathrm{~h}$ focusing. The signal plots appear quite noisy for several reasons: the electrode wires across the coolant channel block out some of the excitation light causing dips in the emission intensity at regular intervals; the emission (before quenching) is more intense in the centre of the channel than at 

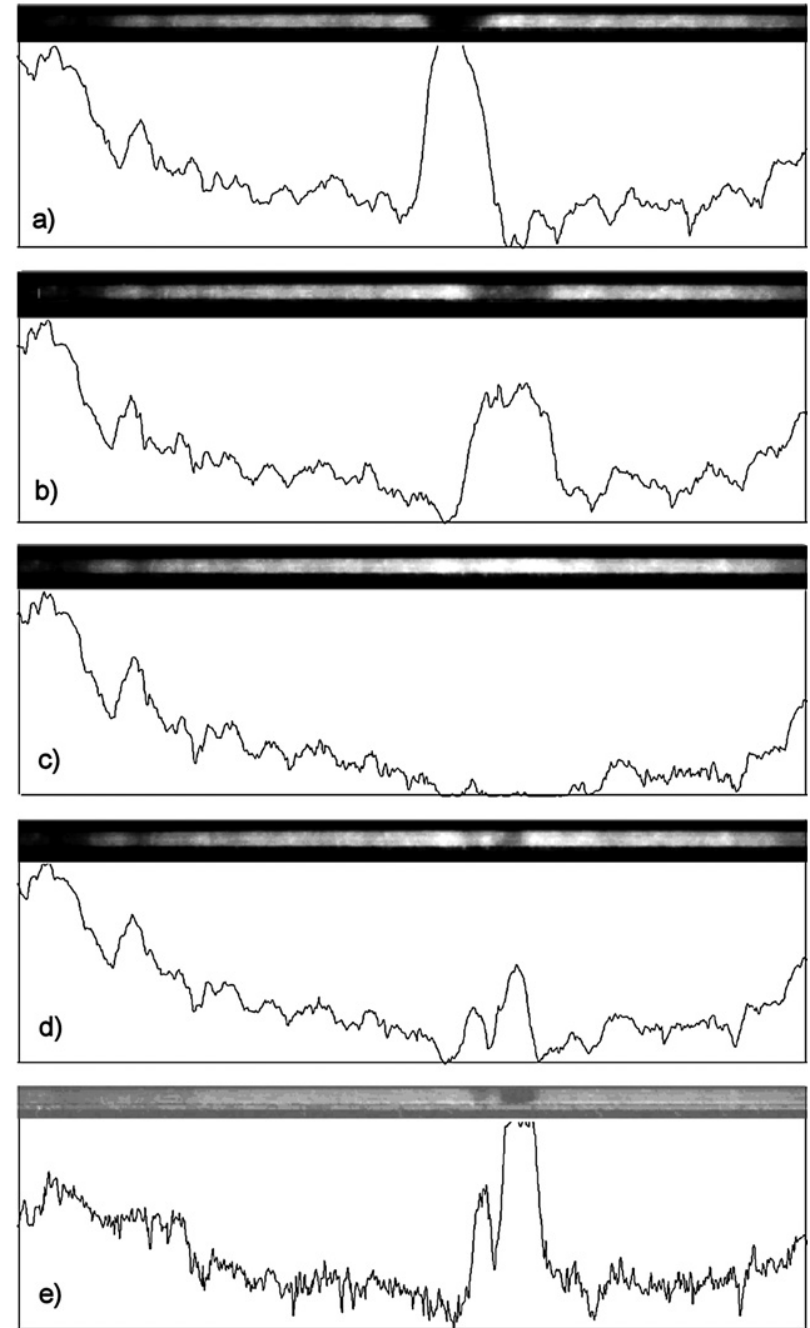

Fig. 4 Focusing of (a) HLADH (100 $\mu \mathrm{g})$ and (b) hemocyanin $(100 \mu \mathrm{g})$, using the FGF21 system, $20 \mu \mathrm{L} \mathrm{h}^{-1}$. Right-hand side corresponds to the inlet (top) of the device. Images are from colour photographs converted to greyscale with equal weighting of RGB channels. Intensity profiles are calculated from the greyscale images using Scion Image. Image (c) shows the column prior to injection and (d) after focusing a mixture of both proteins $(25 \mu \mathrm{g}$ each). Image (e) is calculated by the software by subtracting $0.57 \times(\mathrm{c})$ from $(\mathrm{d})$ and optimising the contrast.

the extremities (Fig. 4c), possibly because the glass waveguide channels are in light which is more intense at this point or because of 'shadows' cast by the ends of the channel; and the emission may also vary due to inhomogeneities in the packing along the channel. Nonetheless, peaks due to the focused analyte can be seen clearly in each case.

The major (EE) fraction of commercial HLADH (Sigma A9589) has a pI of 8.1 and $M_{\mathrm{r}}=80000 .{ }^{22}$ Commercial HC (horseshoe crab type VIII, Sigma H1757) is a mixture of isoforms with $\mathrm{pI} \approx 6$ and $M_{\mathrm{r}}$ $=72000 .{ }^{23,24}$ Therefore $\mathrm{HC}$ is expected to have higher mobility at $\mathrm{pH}$ 8.6; the mobilities as measured by $\mathrm{CE}$ in $20 \mathrm{mM}$ pH 8.6 Tris are 0.14 $\times 10^{-4} \mathrm{~cm}^{2} \mathrm{~V}^{-1} \mathrm{~s}^{-1}$ for HLADH and $2.05 \times 10^{-4} \mathrm{~cm}^{2} \mathrm{~V}^{-1} \mathrm{~s}^{-1}$ for $\mathrm{HC}$ $(\mathrm{ESI} \dagger)$. HC indeed focuses further up the channel $(1.9 \mathrm{~cm}$ from the inlet $v s .2 .3 \mathrm{~cm}$ ). HLADH, having a lower mobility, proceeds further down the channel until it encounters a sufficiently steep electric field that the product $E \times \mu_{\mathrm{ep}}$ balances exactly the hydrodynamic flow.
The peaks in both cases are quite broad, and when a $50: 50$ mix was injected it was not resolved. However, on further dilution two resolved peaks were apparent (Fig. 4d). Although the width of focused bands should theoretically be independent of concentration, ${ }^{16}$ it has been observed previously that the width increases with analyte amount, which may be attributed to the concentrated analyte ions distorting the local electric field. ${ }^{25}$ The separation could be better visualised by subtracting the background photograph taken preinjection as shown in Fig. 4e.

This proof-of-principle study has shown that native, uncoloured proteins can be visualised on-column during focusing by FGF/ DFGF. The visualisation technique should be applicable to all proteins as they all absorb at $254 \mathrm{~nm}$. FGF is applicable to all proteins as long as the electrolyte $\mathrm{pH}$ differs from their $\mathrm{pI}$ - acididc proteins can be separated in normal polarity FGF as described here and basic proteins with reversed polarity. The two proteins here have significantly different electrophoretic mobilities; however, DFGF has been shown to be capable of resolving even the two oxidation states of myoglobin, whose mobilities are much closer under the conditions used. $25 \mathrm{mg}$ amounts of the proteins were readily detected and Fig. $4 \mathrm{e}$ suggests that the detection limit could be an order of magnitude lower, dependent on the extinction coefficient of the particular protein. With optimisation of the excitation intensity, column dimensions and detection parameters it should be possible to improve this further. The resolution of the particular proteins studied was not as good as expected based on studies of coloured proteins in earlier work, ${ }^{18}$ which may be due to interactions between the proteins and the fluorescent packing material. Similar broadening of the focused bands is observed when silica is used as the column packing. Future work will investigate different packing materials containing the $\mathrm{F}_{254}$ indicator and different proteins which possess greater homogeneity.

This work was funded by the BBSRC, grant number BB/ C006771/1.

\section{Notes and references}

1 C. F. Ivory, Sep. Sci. Technol., 2000, 35, 1777-1793.

2 R. T. Kelly and A. T. Woolley, J. Sep. Science, 2005, 28, 1985-1993.

3 W. S. Koegler and C. F. Ivory, Biotechnol. Prog., 1996, 12, 822-836.

4 J. G. Shackman and D. Ross, Electrophoresis, 2007, 28, 556-571.

5 J. G. Shackman, M. S. Munson and D. Ross, Anal. Bioanal. Chem., 2007, 387, 155-158.

6 G. J. Sommer, S. M. Kim, R. J. Littrell and E. F. Hasselbrink, Lab on a Chip, 2007, 7, 898-907.

7 D. N. Petsev, G. P. Lopez, C. F. Ivory and S. S. Sibbett, Lab on a Chip, 2005, 5, 587-597.

8 P. Myers and K. D. Bartle, J. Chromatogr., A, 2004, 1044, 253-258.

9 L. K. Ista, G. P. Lopez, C. F. Ivory, M. J. Ortiz, T. A. Schifani, C. D. Schwappach and S. S. Sibbett, Lab on a Chip, 2003, 2003, 266-272.

10 P. H. Humble, R. T. Kelly, A. T. Woolley, H. D. Tolley and M. L. Lee, Anal. Chem., 2004, 76, 5641-5648.

11 K. F. Warnick, S. J. Francom, P. H. Humble, R. T. Kelly, A. T. Woolley, M. L. Lee and H. D. Tolley, Electrophoresis, 2005, 26, 405-414.

12 P. H. Humble, J. N. Harb, H. D. Tolley, A. T. Woolley, P. B. Farnsworth and M. L. Lee, J. Chromatogr., A, 2007, 1160, 311-319.

13 R. T. Kelly, Y. Li and A. T. Woolley, Anal. Chem., 2006, 78, 25652570.

14 J. K. Liu, X. F. Sun, P. B. Farnsworth and M. L. Lee, Anal. Chem., 2006, 78, 4654-4662.

15 X. F. Sun, P. B. Farnsworth, A. T. Woolley, H. D. Tolley, K. F. Warnick and M. L. Lee, Anal. Chem., 2008, 80, 451-460.

16 Z. Huang and C. F. Ivory, Anal. Chem., 1999, 71, 1628-1632.

17 J. M. Burke and C. F. Ivory, Electrophoresis, 2008, 29, 1013-1025. 
18 P. G. Tuñón, Y. Wang, P. Myers, K. D. Bartle, L. Bowhill, C. F. Ivory and R. Ansell, Electrophoresis, 2008, 29, 457-465.

19 Q. G. Wang, S. L. Lin, K. F. Warnick, H. D. Tolley and M. L. Lee, J. Chromatogr., A, 2003, 985, 455-462.

20 J. W. Sease, J. Am. Chem. Soc., 1947, 69, 2242-2244.

21 P.-O. Larsson and K. Mosbach, Methods in Enzymology, 1976, 44, 183-190.
22 I. Hubatsch, P. Maurer, D. Engel and H. W. Adolph, J. Chromatogr., A, 1995, 711, 105-112.

23 M. Brenowitz, C. Bonaventura, J. Bonaventura and E. Gianazza, Arch. Biochem. Biophys., 1981, 210, 748-761.

24 J. Maddaluno and K. F. Faull, Biochem. Biophys. Res. Commun., 1999, 264, 883-890.

25 N. I. Tracy and C. F. Ivory, Electrophoresis, 2008, 29, 2820-2827. 